\title{
Fatores de risco e o cuidado do enfermeiro na prevenção da úlcera por pressão
}

\author{
Ivonete Gomes de Oliveira*, Mara Lúcia Mattos da Costa*, Renê dos Santos Spezani, M.Sc.**
}

${ }^{*}$ Graduandas em Enfermagem pelo Centro Universitário Plinio Leite (UNIPLI), ${ }^{*}$ Especialista em Terapia Intensiva, Professor Orientador do Centro Universitário Plinio Leite (UNIPLI)

\section{Resumo}

Este estudo tem como objeto de análise o cuidado do enfermeiro na prevenção e tratamento da úlcera por pressão. Trata-se de uma análise bibliográfica realizada por meio de busca de dados na Biblioteca Virtual de Saúde (BVS), valendo-se do material publicado sobre o assunto pela Scielo e Lilacs, além de obras de autores de expressão sobre o assunto, com recorte temporal entre 2003 e 2008, cujos objetivos foram identificar os fatores de risco para o aparecimento e desenvolvimento da úlcera por pressão e analisar o papel do enfermeiro diante da prevenção do problema em questão. Os resultados apontam que o enfermeiro deve se envolver no trabalho de prevenção e tratamento das úlceras por pressão, para que essa enfermidade seja tratada de forma mais eficaz, com o objetivo náo só de cura, mas de minimizar o sofrimento do paciente e de seus familiares.

Palavras-chave: úlcera de pressão, fatores de risco, cuidados de enfermagem.

\section{Abstract \\ Risk factors and nursing care in preventing pressure ulcer}

The aim of this study was to analyze the nursing care to prevent and treat the pressure ulcers. This is a literature review carried out through search in Virtual Health Library, using Scielo and Lilacs database, as well as studies from other important authors on the same topic, from 2003 to 2008 . The objectives were to identify risk factors for the onset and development of pressure ulcer and to analyze nurse's role in preventing the problem in question. The results show that the nurse should get involved in the prevention and treatment of pressure ulcers aiming not only to cure, but to minimize suffering of patients and their relatives.

Key-words: pressure ulcer, risk factors, nursing care. 


\section{Resumen}

\section{Factores de riesgo y la atención de enfermería en la prevención de úlcera por presión}

Este estudio tiene como objeto de análisis la atención de enfermería en la prevención y tratamiento de úlcera por presión. Se trata de una investigación bibliográfica que utilizó la Biblioteca Virtual en Salud y como fuentes de consulta las bases de datos Scielo y Lilacs, además de otros autores de expresión en el tema, entre el 2003 y 2005 . Los objetivos fueron identificar los factores de riesgo para la aparición y desarrollo de la úlcera por presión y analizar el papel del enfermero en la prevención del problema en cuestión. Los resultados muestran que el enfermero debe focalizar e intensificar los cuidados para prevenir y tratar úlceras por presión con el objetivo no sólo de curar, pero de minimizar el sufrimiento del paciente y de los familiares,

Palabras-clave: ulcera por presión, factores de riesgo, atención de enfermería.

\section{Introdução}

A decisão de estudar os fatores de risco para úlcera por pressão e o papel do enfermeiro na sua prevenção e tratamento, decorreu de nossa vivência durante o estágio acadêmico na área hospitalar, no qual observávamos que pacientes com limitaçóes de movimentos físicos e restrição ao leito desenvolviam, com muita freqüência, úlceras por pressão.

A úlcera por pressão é descrita como a lesão localizada na pele, provocada pela interrupção do fornecimento de sangue para a área afetada, geralmente provocada por pressão, cisalhamento, fricção ou uma combinaçáo dos três fatores [1]. Este tipo de lesão resulta em danos aos tecidos subjacentes - tecido subcutâneo, músculo, articulaçôes, ossos, levando à diminuição da circulação sanguínea e conseqüentemente a morte e necrose da pele [2].

$\mathrm{O}$ prejuízo da integridade da pele pode ser causado por diversas condiçóes fisiopatológicas, degenerativas, ou ambas, mas em todos os casos, a formação da úlcera por pressão pode interromper funções que são importantes para a homeostasia orgânica, ocorrendo quando é aplicada sobre a mesma uma pressão maior do que a pressão capilar normal [3]. Destaca-se que a pressáo exercida por uma força perpendicular à pele, resultante da ação da gravidade, ocasiona a oclusão do fluxo sangüíneo do paciente que fica em uma mesma posição no leito. A pressão maior que $25 \mathrm{mmHg}$ impede o fluxo sangüíneo dos capilares nos tecidos moles, causando hipóxia que, se não for avaliada a tempo, evolui para eventual necrose [3].

Por ser de longa duração, apresentar reincidência freqüente e cicatrização difícil, a úlcera por pressáo é considerada uma ferida crônica e representa um problema para os indivíduos afetados, uma vez que lhes acarreta considerável desconforto e influencia no aumento de dias de permanência no hospital, dificultando seu retorno ao convívio familiar [4]. Também induz à necessidade de tratamentos cirúrgicos e fisioterápicos, além de afetar a auto-imagem e auto-estima dos pacientes, levandoos a evidenciar problemas emocionais, psicossociais e econômicos [5].

Desta forma, o problema traz para o enfermeiro uma vasta variedade de responsabilidades com as quais se depara ao longo das fases de planejamento, coordenação e implementação da assistência, nas quais deve atuar com equipamentos e materiais específicos, como educador e elaborador de rotinas e procedimentos, bem como no envolvimento e no desenvolvimento das pesquisas a ele relacionadas [6].

Apesar de tudo o que já se sabe sobre o assunto, a úlcera por pressão constitui uma preocupação secular para os enfermeiros que prestam assistência a pacientes acamados. Entretanto, os avanços científicos observados, no que tange à questão, não se mostram suficientemente satisfatórios para erradicar o avanço deste agravo e as complicaçóes que dele derivam.

Diante desse contexto, elegemos para o desenvolvimento deste estudo as seguintes questóes norteadoras:

1. Quais são os fatores de risco para o desenvolvimento da úlcera por pressão?

2. Como o conhecimento acerca dos fatores de risco pode orientar o enfermeiro na prevenção e tratamento da úlcera por pressão?

Neste sentido, este estudo tem como objetivos identificar os fatores de risco para o início da úlcera por pressáo e analisar o papel do enfermeiro diante da prevenção e tratamento do problema em questão.

Acreditamos que o correto entendimento dos fatores de risco para o desenvolvimento das úlceras 
por pressáo, bem como a necessidade premente em se reduzir seus elevados índices nas instituiçóes hospitalares mostram-se relevantes e justificam a intenção em realizar este estudo, num momento em que se busca consumar na prática o discurso da qualidade da assistência em saúde.

Dessa forma, pressupomos que este trabalho possa contribuir com subsídios teóricos que poderão fundamentar o enfermeiro na orientação dos profissionais de sua equipe, resgatando e ampliando seus conhecimentos prévios acerca da temática em discussão, levando-os a refletir sobre suas ações e os estimulando a buscar e lutar por medidas mais efetivas na prevenção e tratamento da úlcera por pressão.

\section{Materiais e métodos}

A fim de atingir o objetivo proposto, utilizamos como estratégia metodológica a revisão bibliográfica, que pode ser bastante útil no processo de familiarização do pesquisador com a teoria relevante e de indicar as estratégias, procedimentos e instrumentos específicos que possam trazer resultados na solução do problema objeto do estudo e aumentar a probabilidade de ser feito um novo estudo que trará uma contribuição diferente ao conhecimento $[7,8]$.

Para elucidar o problema da pesquisa, utilizamos os dados levantados na biblioteca Virtual de Saúde (BVS), valendo-nos do material publicado sobre o assunto pela Scientific Eletronic Library on-line (Scielo) e pela Literatura Americana e do Caribe em Ciências da Saúde (Lilacs), no período de 2005 a 2008. Foram utilizados os descritores: úlcera por pressão, fatores de risco, cuidados de enfermagem. Os dados foram analisados de forma crítica e reflexiva, e procuramos articular o nosso pensamento com o de autores de expressão, em obras consideradas de maior relevância e interesse para a temática em questáo.

\section{Resultados e discussão}

As úlceras por pressão são freqüentes em pacientes acamados por longos períodos, podendo trazer sérias complicaçóes, como osteomielite, septicemia, amputaçóes, ou mesmo levar o paciente a óbito. Além das perdas financeiras ocasionadas ao paciente e aos familiares, o problema traz, também, transtornos psicológicos que impedem ou dificultam a participação do indivíduo em programas de reabilitação [5]. Assim, a prevenção e tratamento no estágio inicial deve ser a meta da assistência que vise à qualidade $[5,9]$.

A úlcera por pressão é um dos principais exemplos de integridade da pele prejudicada e representa uma ameaça direta para o indivíduo, causando desconforto, prolongamento da doença, demora na reabilitação e alta, visto que dá origem a uma perda notável de proteínas orgânicas, fluidos e eletrólitos, originando uma debilidade progressiva que pode permitir, ao longo do tempo, a entrada de microrganismos infecciosos no corpo humano, refletindo sistemicamente $[5,6]$.

Por todos os efeitos nocivos que pode ocasionar ao paciente, a presença das úlceras por pressáo tem sido apresentada como um indicador da qualidade de assistência dos serviços de saúde e despertado em inúmeros profissionais que atuam neste ramo específico um maior interesse pela adoção de medidas adequadas que visem a educação para prevenção dirigida a profissionais, pacientes e familiares $[6,9]$. Embora outros profissionais da equipe de saúde devam estar envolvidos pela natureza multicausal do problema, a manutenção da integridade de pele e tecidos subjacentes tem sido, tradicional e erroneamente, considerada uma responsabilidade quase que específica da equipe de enfermagem.

Neste sentido, as equipes de enfermagem, preocupadas com a questão, têm-se utilizado de protocolos e escalas de estratificaçáo preditiva de riscos, principalmente as escalas de Norton e Braden, como complementos na avaliação e conduta [10].

Com relação ao fato, a literatura pesquisada destaca uma extensa referência a fatores de risco intrínsecos e extrínsecos para úlcera por pressão. Fatores extrínsecos sáo aqueles relacionados ao mecanismo de lesão, influenciando a tolerância tissular pelo impedimento da circulaçáo sobre a superfície da pele e refletem o grau em que a pele é exposta à força de pressáo, à umidade, ao cisalhamento e/ou à fricção. Por outro lado, fatores intrínsecos são os relacionados às variáveis do estado físico do paciente, que influenciam tanto a arquitetura e integridade da pele e estruturas de suporte, e/ou o sistema vascular e linfático que servem à pele e estruturas internas, quanto ao tempo de cicatrizaçáo [3].

A literatura mostra, ainda, que foi descrito um esquema conceitual para o estudo da úlcera por pressão. De acordo com este esquema, a intensidade e duração da força de pressão no corpo e a tolerância do tecido determinam o desenvolvimento da úlcera 
por pressão. Ficou provado também que existe um relacionamento inverso entre a duração e a intensidade da força de pressão na criação da isquemia tissular [2]. Uma força de pressão de intensidade baixa, por um longo período de tempo, pode gerar dano ao tecido, do mesmo modo que uma força de alta pressão, por um período curto de tempo. Isto está relacionado à tolerância tissular que pode estar reduzida [10].

Efeitos similares são ocasionados pela fricção que provoca a descamaçáo epitelial e enfraquece a barreira natural da epiderme [1] e é apontada como um importante fator de risco que ocorre quando a pele do paciente sofre força de atrito contra uma superfície, freqüentemente quando o paciente é arrastado na cama.

O cisalhamento é outro fator de risco. Trata-se de uma pressão exercida quando o paciente é movido ou reposicionado na cama ou na cadeira $[5,10]$. Quando o paciente desliza pelo leito ou cadeira, a pele adere à superfície enquanto as camadas de tecido subcutâneo e até mesmo os ossos, deslizam na direção do movimento do corpo. Nota-se que fricção está sempre presente quando o cisalhamento acontece [1].

Por outro lado, a umidade prolongada também contribui para as úlceras por pressão, causando maceraçóes à pele e reduzindo sua resistência à tração. Neste caso, a pele pode se tornar úmida, pela sudorese, pelas eliminaçôes vesicais, eliminaçôes intestinais ou drenagem de fístulas ou feridas [1]

A ausência de rotina na mobilização do paciente acamado é o fator de risco mais apontado para o desenvolvimento da úlcera por pressáo. Todos os estudos sobre a prevenção da úlcera por pressão deixam bem clara a necessidade de mobilizar periodicamente os pacientes acamados em intervalos não superiores a duas horas [6,9], uma vez que a mudança de posição do paciente alivia a pressão sobre o tecido afetado e aumenta o fluxo sanguíneo no local.

Para nós, enfermeiros, este fator se acirra, sobretudo nos casos em que o paciente apresenta habilidade diminuída para perceber ou responder aos estímulos, pois a diminuição da sensação cutânea interfere na percepção da dor. Náo estando consciente do distúrbio associado com a pressão prolongada sobre a pele, ele náo reposiciona seu corpo na intenção de aliviar a pressão [9]. Até mesmo nos pacientes com alguma habilidade para mudar a posição do corpo como os paraplégicos, a sensação de necessidade dessa mudança pode não estar presente [2].

A higiene inadequada do paciente é citada também como um fator de risco, uma vez que, sendo realizada, mantém-se o paciente livre de impurezas, tais como umidade por suor, diurese, fezes e outras secreções; ativa-se a circulação sangüínea e, ao mesmo tempo, mobiliza-se o paciente, contribuindo, de maneira significante, para a manutenção da integridade da pele [10].

Outro fator destacado pela literatura refere-se ao leito sobre o qual repousa o paciente, que deve ter pelo menos $13 \mathrm{~cm}$ de espessura e, como a espuma tem uma vida útil em torno de 04 anos, é necessário ter um programa de reposiçáo do mesmo. $\mathrm{O}$ colchão deve ser adequado às condiçóes do paciente $\mathrm{e}$ seu forro não deve possuir dobras que favoreçam a formação de úlceras de pressão [2].

Ainda em relação a riscos extrínsecos para úlcera por pressáo, alguns autores [1,3,9], observam que deve ser dada atençáo à roupa de cama do paciente. Os lençóis devem estar sempre limpos, secos e bem esticados, sem dobras e sem presença de corpos estranhos que possam irritar a pele do paciente, favorecendo assim a formação das úlceras de pressão.

Como já se afirmou, os fatores de risco categorizados como intrínsecos são aqueles relacionados às variáveis do estado físico do paciente [4]. O estado geral do paciente é importante, uma vez que o corpo pode enfrentar uma pressão externa maior quando está saudável do que quando está doente.

Desta forma, a mobilidade ou a atividade reduzida, que pode estar também associada a alteraçóes neurológicas, tais como paraplegia, hemiplegia, tetraplegia, acidente vascular cerebral, contribui para o desenvolvimento de úlceras por pressão. A imobilidade diminui a capacidade do paciente em aliviar a pressão devido à habilidade diminuída para mudar e controlar a posiçáo do corpo, o que aumenta a probabilidade de que ele esteja exposto a prolongada e intensa pressáo e, consequentemente, ao desenvolvimento de úlceras por pressão [1].

Acreditamos que este fator se mostra ainda mais relevante no envelhecimento, fase em que diversas mudanças ocorrem na pele, tais como: diminuição da massa corporal; diminuição dos níveis de soro albumina; diminuição da resposta inflamatória; redução na quantidade de fibras elásticas; diminuição do colágeno dérmico, tanto em quantidade como em qualidade e a diminuição 
da adiposidade do tecido subcutâneo. Os idosos apresentam, também, diminuição da eficiência do sistema respiratório, circulatório, renal, muscular, sensorial e nutricional, justificando, portanto, a unanimidade entre os pesquisadores em indicá-los como predisponentes para o desenvolvimento de úlceras por pressão [3].

Como outro agravante, pode-se destacar também que a nutrição deficiente tem sido indicada por inúmeros estudos como um fator significante no desenvolvimento de úlceras por pressão, uma vez que a deficiência de proteínas e vitaminas deixa os tecidos mais susceptíveis à integridade da pele prejudicada, quando expostos à pressáo. A deficiência de certas vitaminas, em particular a vitamina C, que é necessária à pele para vitalidade e cicatrização tissular, produção de fibroblastos, formação do colágeno e aumento da resistência do indivíduo, também contribui para o desenvolvimento de úlcera por pressão. Ressalta-se que a vitamina $\mathrm{C}$ em quantidades inadequadas contribui para a fragilidade capilar, ficando os tecidos predispostos a traumas e à interrupção do fluxo sangüíneo [10-12].

No que tange à questáo, diversos autores [1,4,9-13] também apontam os casos extremos de emagrecimento e obesidade como fatores de risco para úlcera por pressão. No emagrecimento, a musculatura se torna hipotrófica e o panículo adiposo escasso. Os pacientes que emagrecem não têm enchimento de gordura sobre as saliências ósseas, portanto têm menos proteçáo à pressáo [1]. $\mathrm{Na}$ obesidade, o paciente está com o peso corpóreo em torno de $20 \%$ ou mais do peso ideal, o que provoca um isolamento térmico excessivo, e pode causar uma reduçáo das perdas de calor normais $[4,10]$. Existe, também, maior dificuldade em se mobilizar os pacientes obesos e, geralmente, são arrastados na cama ou cadeira durante a mobilizaçáo, o que pode levar a lesão do tecido [13].

Por sua vez, a anemia, seja qual for a causa, diminui a capacidade de transporte de oxigênio no sangue e predispóe à formação da úlcera por pressão [3]. Certas doenças como o diabetes, a doença cardíaca, a doença vascular periférica causam uma diminuição no fornecimento de sangue para a periferia, diminuindo a pressão capilar, provocando nutriçáo inadequada dos tecidos [1].

Em uma pesquisa desenvolvida para identificar as variáveis associadas com úlcera por pressão foi identificado que os principais fatores preditivos para úlcera por pressáo foram: nível de atividade e mobi- lidade, lesão medular completa, presença de incontinência e disreflexia autonômica. Os pesquisadores concluíram que as pessoas com risco mais elevado precisam ser avaliadas de forma mais freqüente $\mathrm{e}$ participar de programas de prevenção [9].

Assim, a atuaçáo da equipe de enfermagem na prevenção do problema foi destacada nas diretrizes para a prática clínica do órgão do governo norte-americano, Agency for Heath Care Policy and Research [2]. Tais diretrizes foram construídas por especialistas e têm sido utilizadas no mundo todo para nortear a assistência dentro do modelo da Medicina Baseada em Evidências.

Deste modo, inúmeras são as recomendaçóes no sentido de se enfocar as açóes necessárias para a prevençáo da úlcera por pressáo dentro de quatro aspectos básicos: avaliação do risco do paciente e dos fatores que o colocam em risco; cuidados com a pele e tratamento precoce da úlcera; redução da carga mecânica pelo reposicionamento e utilização de superfícies especiais de suporte, como almofadas e colchôes; educação de pacientes, cuidadores e fornecedores de serviços [2]. Essas diretrizes trouxeram o enfoque para os fatores de risco, relacionados às questôes psicossociais, como os comportamentos, condiçóes econômicas, estilos de vida e adaptação psicológica de pacientes e familiares [11-13].

Assim, tendo em vista a grande dificuldade na sua cura, acreditamos que todo esse panorama ocasiona às enfermeiras e enfermeiros de todo o mundo muitas oportunidades de assistência direta e preventiva às úlceras por pressão nos pacientes acamados, o que nos induz a pensar que o papel da enfermagem se torna mais importante na prevenção do que na cura [2].

A nosso ver, essas diretrizes vêm, paulatinamente, modificar e desmitificar um antigo paradigma, pois durante muito tempo a enfermagem carregou a culpa pela ocorrência da úlcera por pressáo, sendo a mesma considerada como resultante de uma assistência de enfermagem precária [5]. Hoje, a equipe de saúde deve ter consciência da série de fatores que podem influenciar a resposta tecidual à pressão e a busca de soluçóes para os mesmos deve ser uma preocupação inerente a toda a equipe, tendo-se como meta a diminuiçáo ou reduçáo do risco do paciente para desenvolver a úlcera através da instituição de estratégias de prevenção apropriadas $[5,12,14]$.

No que diz respeito à assistência prestada pelo enfermeiro, sugere-se que esta seja pautada na prática atualizada, abarcando a coordenaçáo, 
a educação, o planejamento, o interesse e a participação nas pesquisas e na produção científica, de modo a facilitar o uso de equipamentos, a educação em saúde, a elaboração e implementação de rotinas e a realizaçáo dos cuidados de forma correta para atender as reais necessidades apresentadas pelos pacientes $[10,15]$.

Acreditamos que a conscientização do enfermeiro sobre a complexidade da assistência de enfermagem, com qualidade em dermatologia pode ser considerada como decisivo fator para a prevenção da úlcera por pressão com uma técnica padronizada, simples e possível de ser delegada aos profissionais de nível médio da enfermagem [9].

Entretanto, salientamos que em todos os casos, tanto a prevenção quanto o tratamento requerem um planejamento individualizado, precisa e exige dedicação, intenso preparo, especialização e atualização constante do profissional, tanto nas questóes teórico-práticas como em relação aos avanços tecnológicos, para uma intervençáo de enfermagem competente e eficaz $[2,5]$.

Evidentemente, por permanecer a maior parte do tempo ao lado dos pacientes, cabe aos profissionais enfermeiros, entre outras responsabilidades, a manutenção da integridade da pele do paciente, sendo necessário para isto, que se estabeleçam condutas que garantam a ausência ou que minimizem a ação dos fatores que contribuem para a alteração dessa integridade. Para garantir uma assistência de enfermagem qualificada a pacientes acamados, tendo como meta a prevenção da ocorrência de úlceras por pressão, tem sido recomendado o conhecimento e a utilização de escalas para avaliação do risco a que essa clientela está submetida [3].

Afirma-se que um sistema de classificação é útil para planejar os cuidados que serão prestados ao paciente, mas que estes são limitados, uma vez que são aplicados de acordo com a descrição visual, não representando de forma exata a extensão das lesôes nos tecidos [9]. Refere-se que a abertura na pele superficial é quase sempre menor do que o orifício na musculatura subjacente [3], de modo que uma lesão da pele pode representar somente a ponta do iceberg, a exemplo das úlceras fechadas ou que estáo na fase inicial, necessitando, para que sua avaliação seja objetiva e mais agressiva, através de desbridamento [3].

No que tange à assistência de enfermagem, as pesquisas identificam que algumas abordagens devem ser revistas e levadas em consideraçáo pelos enfermeiros para prevenir a úlcera por pressão. As mudanças de decúbito dos pacientes acamados ou debilitados devem ser realizadas de 2 em 2 horas e sempre evitar deixar o paciente em atrito com a área lesada. Para as mudanças de decúbito devem ser considerados os déficits neurológicos, lesão músculo-esqueléticas ou áreas particulares da pele com risco elevado de formaçáo de úlceras [1,9]. O paciente nunca deve ficar posicionado diretamente sobre a úlcera, e se isto não for possível, ele deve estar sobre uma superfície redutora de pressão.

Para evitar as lesóes causadas pelo contato das proeminências ósseas umas com as outras, recomenda-se o uso de travesseiros, cunha de espuma ou outros dispositivos para manter os joelhos e os tornozelos separados. Ratifica-se que qualquer pessoa com mobilidade comprometida que esteja restrita ao leito deve ter um dispositivo que alivie totalmente a pressão sobre os calcanhares fora do leito. Isto pode ser feito simplesmente colocando-se travesseiros sob as pernas ou pode incluir dispositivos mais complexos. Almofadas em forma de rosca nunca devem ser usadas pelo paciente com risco de desenvolver úlceras de pressão. Não se devem utilizar luvas de látex, nos calcanhares do paciente, pois este procedimento pode ocasionar o aparecimento de úlceras por pressão. Colchonetes especiais contendo ar, espuma, gel ou água, devem ser utilizados com a profundidade recomendada de $13 \mathrm{~cm}$ para os com gel e de $7,5 \mathrm{~cm}$ para os com água $[1,2,4,9]$.

Quanto às massagens de conforto com ácidos graxos essenciais, ressalta-se que estas podem ocasionar um alívio da dor e auxiliar na circulação sanguínea, evitando o aparecimento das úlceras por pressão. Porém, devem ser evitadas as massagens nas proeminências ósseas, pois as evidências atuais sugerem que massagem pode causar mais danos à pele $[1,2,4,9]$.

Com relação à higienização, a pele deverá ser limpa no momento que se sujar ou em intervalos de rotina. A freqüência de limpeza deve ser individualizada de acordo com a necessidade ou preferência do paciente $[1,2,4,9]$. Faz-se necessário, também, diminuir os fatores ambientais que levam ao ressecamento da pele como: umidade baixa (menos que quarenta por cento) e exposiçáo ao frio e tratar a pele seca com cremes hidratantes.

Cabe destacar também que a exposição da pele à umidade devido à incontinência urinária, perspiração ou drenagem de feridas deve ser minimizada. Quando essas fontes de umidade não podem ser 
controladas, o enfermeiro deve encorajar o uso de fraldas descartáveis ou forros feitos de materiais que absorvam a umidade e que mantenham seca a superfície em contato com a pele. Para tanto, agentes tópicos que agem como barreira para umidade como cremes, películas protetoras ou óleos também podem ser usados [6].

Para evitar as lesôes da pele devido à fricção e força de cisalhamento, o enfermeiro deve dispensar uma atenção especial para instituir um posicionamento adequado e uso de técnicas corretas para transferência e mudança de decúbito. Além disso, deve ter em mente que os danos causados pela fricção podem ser reduzidos pelo uso de lubrificantes, películas protetoras (como curativos transparentes e selantes para a pele) e curativos protetores. Recomenda-se também que os pacientes não sejam arrastados durante a movimentação, mas que sejam erguidos utilizando-se o lençol móvel [11].

Se existe um potencial para melhorar a mobilidade do indivíduo e o estado de atividade, o enfermeiro deve atuar conjuntamente com outros membros da equipe multidisciplinar para ampliar o nível atual de atividade, mobilidade e amplitude de movimentos [6].

Quanto ao estado nutricional, pode-se dizer que a participação do enfermeiro é de extrema importância para os pacientes acamados, pois a dificuldade de se alimentar pode ocasionar uma perda de peso involuntária, imobilidade, estado mental alterado e déficit cognitivo [9]. As diretrizes recomendam que esse profissional deve encorajar e auxiliar a ingestáo dietética e a suplementação da dieta. Se o indivíduo estiver desnutrido, recomendase auxílio nutricional através de sonda ou outros meios necessários [10].

Os aspectos psicossociais necessitam muito do auxílio dos enfermeiros, pois inclui o fato de que o paciente precisa compreender o plano de tratamento e estar motivado para aderir ao que foi planejado, necessitando compreender valores, e se adaptar a um estilo de vida adequado [11]. Estes recursos não são apenas financeiros, mas também incluem a capacidade de entender e acompanhar o plano de tratamento.

Quando indivíduos aparentemente bem nutridos desenvolvem uma ingestáo inadequada de proteínas ou calorias, os enfermeiros devem primeiro tentar descobrir os fatores que estáo comprometendo a ingestâo e então oferecer uma ajuda na alimentação [12]. Às vezes outros suplementos nutricionais podem ser necessários. Se a ingestão dietética continuar inadequada e se estiver de acordo com os objetivos gerais da terapia, intervenções nutricionais mais agressivas como alimentação parenteral ou enteral devem ser consideradas.

Para indivíduos comprometidos nutricionalmente um plano de suporte nutricional e ou suplementaçáo deve ser implementado desde que atenda as necessidades do indivíduo e esteja dentro dos objetivos gerais da terapia [13].

Todas as intervençóes e resultados devem ser monitorados e documentados no prontuário. Estes parâmetros auxiliam na prevenção da úlcera por pressão, mas para cada paciente deve se criado um plano de mudança de decúbito, pois este plano deve ser individual uma vez que depende da imobilidade de cada paciente, porém, para que seja prestada uma assistência adequada ao paciente, é necessária a cooperação principalmente do paciente e de sua família [14].

Para finalizar, cabe ainda destacar que alguns aspectos na educação para prevenção das úlceras por pressão apontam essa diretriz como uma das principais implicaçóes para a prática do enfermeiro que deve encorajar a independência dos pacientes nas fases mais tardias do programa de reabilitaçáo, sabendo que para os pacientes constitui-se uma meta conseguir sua independência nas atividades da vida diária [15]. No entanto, para que se consiga isso, é preciso ensinar ao paciente como cuidar da pele e como evitar outras lesóes similares, pois a cada lesão, o programa fica praticamente interrompido, retardando o processo de reabilitação [15].

Deste modo, acreditamos que a prevenção deve ser abordada pelo enfermeiro como um hábito a ser desenvolvido pelo paciente e sua família e, para tanto, é necessário buscar compreender a dinâmica familiar, identificar e caracterizar o cuidador ou o familiar com potencial para isso e, principalmente, possibilitar que sejam ativamente partícipes destes cuidados, conhecendo fatores de risco e atuando na elaboraçáo do programa de prevenção de úlcera por pressão o mais precocemente dentro de suas condiçôes gerais e de evolução clínica [13].

\section{Conclusão}

$\mathrm{Na}$ literatura pesquisada, foi possível observar que as úlceras por pressão são apresentadas como deficiência na qualidade da assistência de enfermagem prestada. Entretanto, a nosso ver, afirmativas 
como essas penalizam excessivamente a profissão por não levar em consideraçáo aspectos administrativos e organizacionais dos hospitais e serviços de saúde que, certamente, estáo envolvidos na questão da qualidade da assistência. Inclui-se aqui a adequação qualitativa e quantitativa de recursos humanos e materiais para a prestação de um cuidado de enfermagem livre de riscos para o paciente.

Faz-se notar, também, a preocupação de alguns pesquisadores em eximir o sentimento de culpa que recai, principalmente, sobre a enfermagem, quanto ao aparecimento da lesão, demonstrando, através das evidências científicas, que o problema vai além do cuidado em enfermagem, dividindo com extrema crítica e bom senso sua responsabilidade com outros membros da equipe multidisciplinar, destacando, portanto a necessidade de haver uma participação coletiva e compartilhada desses mesmos atores na luta pela diminuição do problema em questão no âmbito das competências de cada um.

Náo é raro se notar que em instituiçóes hospitalares, o paciente acamado com perda da mobilidade e sensibilidade torna-se dependente de outra pessoa para se mobilizar. Mas a estrutura da instituição e o processo de cuidar, na maioria das vezes, não atende às necessidades do paciente e dos profissionais enfermeiros, ratificando que, para prevenir o problema, torna-se necessário a utilizaçáo de abordagens que lidem com todo o sistema, integrando o paciente e o ambiente institucional de forma adequada.

Após a alta, o problema persiste, pois se a família não tem conhecimento a respeito da prevenção, não prestará os cuidados adequados em casa. Dessa forma, cabe ao enfermeiro desenvolver açóes que visem educar e orientá-la quanto aos cuidados com o paciente acamado, visando à prevenção da úlcera por pressão.

É necessário que o enfermeiro esteja preparado para realmente cuidar integralmente dos pacientes que buscam qualidade de vida mesmo no estado de doença. Para tanto, deve realizar revisóes periódicas na literatura para a atualizaçáo de seus procedimentos, pois tudo isso influi na prática e no desenvolvimento da melhoria na qualidade da assistência. A construção do conhecimento e a utilização dos resultados são processos interdependentes, e essenciais para $\mathrm{o}$ avanço da prática científica de enfermagem, e para que se efetivem é importante a seleção de um modelo teórico para a difusão desse conhecimento.

Assim, o resultado desta pesquisa demonstra que o enfermeiro deve estar sempre ampliando seus conhecimentos, no sentido de atualizar seus procedimentos, compartilhando os achados com sua equipe, com o paciente e com sua família, pois é esse conhecimento que irá influir na melhoria da qualidade da assistência, além de tornar os enfermeiros profissionais mais competentes e capacitados para exercer com dignidade a nossa profissão.

\section{Referências}

1. Irion, GL. Feridas: novas abordagens, manejo clínico e atlas em cores. Rio de Janeiro: Guanabara Koogan; 2003.

2. Nogueira PC, Caliri MHL, Santos CB. Fatores de risco e medidas preventivas para úlcera por pressão no lesado medular. Experiência da equipe de enfermagem do HCFMRP-USP Rev Med 2002;35(1):14-23.

3. Smeltzer CS, Bare GB. Tratado de enfermagem médicocirúgica. 10 ed. Rio de Janeiro: Guanabara Koogan; 2005.

4. Figueiredo NMA, Silva CRL, Silva RCL. CTI: atuação, intervenção e cuidados de enfermagem. São Caetano do Sul: Yendis; 2006.

5. Rangel EML, Rustici AKF, Prado KG, Machr YAL, Bertolo FS, Silva FS, Caliri MHL. Conhecimento e percepçóes de graduandos em enfermagem sobre a prevenção e tratamento de úlceras de pressáo. [Resumos]. Apresentado no IV Simpósio de Iniciação Científica da Universidade de São Paulo; Novembro 2003; Ribeirão Preto.

6. Costa IG. Incidência de úlcera por pressão e fatores de risco relacionados em pacientes de um centro de terapia intensiva [dissertação]. Ribeirão Preto: Escola de Enfermagem de Ribeirão Preto da USP; 2003.

7. Gil AC. Como elaborar projetos de pesquisa. 4a ed . São Paulo: Atlas; 2006.

8. Polit DF, Beck CT, Hungler BP. Fundamentos de pesquisa em enfermagem: métodos, avaliação e utilização. 5a ed. Porto Alegre: Artmed; 2004.

9. Dealey C. Cuidando de feridas: um guia para as enfermeiras. São Paulo: Atheneu; 2004.

10. Potter PA, Perry AG. Grande tratado de enfermagem prática: clínica e prática hospitalar. São Paulo: Santos; 2002.

11. Silva MSML. Fatores de risco para úlcera por pressão em pacientes hospitalizados [tese]. João Pessoa: Universidade Federal da Paraíba; 1998. 89p.

12. Pinheiro MRB, Figueiredo LMB, Guariente MHDM, Haddad MCL. Fatores de risco para o desenvolvimento de úlcera por pressão em paciente crítico: estudo de caso [online]. [citado 2008 Mar 12]. Disponível em URL http://www.publisaude.com.br/portal.

13. Fernandes LM. Úlcera por pressão em pacientes críticos hospitalizados: uma revisão integrativa da literatura [Tese]. Ribeirão Preto: Escola de Enfermagem de Ribeirão Preto da USP; 2002.

14. Costa IG. Incidência de úlcera por pressão e fatores de risco relacionados em pacientes de um centro de terapia intensiva [Dissertação]. Ribeiráo Preto: Escola de Enfermagem de Ribeirão Preto da USP; 2003.

15. Giovanini T, Junior AGO, Palermo TCS. Manual de Curativos. São Paulo: Corpus; 2007. 